\section{Direct Demonstration of the Human Parvovirus in Erythroid Progenitor Cells Infected In Vitro}

\author{
Neal Young, Maria Harrison, Jeffrey Moore, \\ Philip Mortimer, and R. Keith Humphries \\ Clinical Hematology Branch, National Heart, Lung, and Blood \\ Institute, Bethesda, Maryland 20205; Central Public Health \\ Laboratory, Virus Reference Laboratory, \\ Collindale, London, England
}

bstract. The human parvovirus (HPV), the cause of transient aplastic crisis of hereditary hemolytic anemia, has been shown to be cytotoxic for erythroid progenitor cells and its presence in these cells demonstrated by morphologic techniques. A relatively pure population of progenitors, isolated by removal of immature erythroid bursts from primary culture, was the target of the virus infection. Infected cells failed to proliferate in secondary culture. Using a monoclonal antibody to HPV, specific fluorescence was demonstrated in a minority of cells $24-48 \mathrm{~h}$ after infection with virus. Infected cells examined by electron microscopy showed marked toxic ultrastructural alterations and parvoviruslike particles in crystalline arrays in the nucleus.

\section{Introduction}

Parvoviruses, the smallest DNA-containing animal viruses, are responsible for a wide variety of diseases in mammals and birds (1). In 1975 parovirus-like particles were discovered in the sera of blood donors during an investigation of an anomalous serologic reaction (2). Antibody to the antigen of these particles was found to be common in the adult population (3). Screening of sera of children revealed the presence of the anitgen and IgM-type antibody to it among children with sickle cell disease who suffered from aplastic crises $(4,5)$, and evidence of acute infection with this agent preceding erythroblastopenic crises has now accumulated for several different hemolytic diseases (6). In normal children, the virus has been implicated as the etiologic agent in the common childhood exanthem called fifth disease (7). There is now strong evidence

Address correspondence to Dr. Young, National Heart, Lung, and Blood Institute.

Received for publication 18 May 1984 and in revised form 16 August 1984.

The Journal of Clinical Investigation, Inc.

Volume 74, December 1984, 2024-2032 that the virus is a parvovirus $(8,9)$, and it is generally referred to as human parvovirus (HPV). ${ }^{1}$

We have investigated the mechanism by which HPV inhibits erythropoiesis. Sera containing HPV are potent inhibitors of erythroid colony formation in vitro, and the inhibitory effect is specific for erythroid compared with myeloid progenitor cells (10). Only the virus-particle containing fraction of sera is inhibitory, and antibody to the virus can neutralize its activity $(10,11)$. A target of HPV can be demonstrated to be an erythroid progenitor cell by experiments in which maturing erythroid colonies are separated from other cultured bone marrow cells before infection $(11,12)$. We report the analysis of such isolated cells using a variety of techniques, including serial in situ observation, immunofluorescence with a specific monoclonal antibody to HPV, and electron microscopy. These studies show that HPV is cytotoxic for human erythroid progenitor cells and demonstrate HPV in the nucleus and ctyoplasm of red cell precursors.

\section{Methods}

Source of HPV and anti-HPV monoclonal antibody. Sera drawn from two patients (JB and $\mathrm{JH}$ ) with congenital hemolytic anemias and transient aplastic crisis served as the source of HPV; these sera behave identically in tissue culture experiments (11) and are of similar antigenic potency (10). A murine hybridoma $\operatorname{IgG}$ antibody to HPV (from blood donor B19) was prepared as described (3).

Cell culture. Bone marrow aspirates were obtained from normal volunteers who had given informed consent; mononuclear cells were separated by sedimentation through Percoll (Pharmacia Fine Chemicals, Piscataway, NJ). Bone marrow mononuclear cells were grown in methylcellulose medium with growth factors to promote formation of erythroid colonies derived from the primitive progenitor, BFU-E, and more mature progenitor, CFU-E $(11,12)$. Erythroid bursts, derived from the BFU-E, require 2-3 wk to reach full maturity in culture; however, immature nonhemoglobinized bursts can be recognized by their morphologic features at $1 \mathrm{wk}$ and removed from primary culture with a micropipette. Isolated cells from colonies at this stage of development represent a pure population of erythroid progenitors

1. Abbreviation used in this paper: HPV, human parvovirus. 
similar to CFU-E and on replating in fresh medium will form secondary erythroid colonies with a high plating efficiency (11).

To infect cells, 20-100 immature bursts were removed to $50 \mu \mathrm{l}$ of Iscove's modification of Dulbecco's medium that contained 2\% fetal calf serum in 1.5-ml Eppendorf bullet tubes (Brinkmann Instruments Inc., Westbury, NY). Cells were suspended in either HPV-containing or normal sera to a final concentration of $10^{-3}$ for $2 \mathrm{~h}$ at $4^{\circ} \mathrm{C}$. To measure and observe intact erythroid colonies, cells in $1 \mathrm{ml}$ of tissue culture medium were transferred to $35-\mathrm{mm}$ suspension culture dishes (Lab-Tek; Miles Laboratories, Elkhart, IN); for experiments in which cells were to be isolated, $0.5 \mathrm{ml}$ of tissue culture medium was added to each bullet, the tubes covered with perforated Parafilm (American Can, Greenwich, CT), and cultured for 24,48 , or $72 \mathrm{~h}$ at $37^{\circ} \mathrm{C}, 95 \%$ humidity, and $5 \% \mathrm{CO}_{2}$ before harvesting. To recover cells, the Eppendorf tubes were centrifuged in a Beckman Microfuge 12 (Beckman Instruments Inc., Palo Alto, CA) for $7 \mathrm{~min}$ at 1,000 rpm. Supernatants were gently removed and the cells washed twice in phosphate-buffered saline (PBS), pH 7.5. For conventional staining and immunofluorescence cells were pelleted onto slides using a Cytospin 2 (Shandon Southern Instruments, Sewickley, PA) cytocentrifuge, $500 \mathrm{rpm} \times 10 \mathrm{~min}$.

Immunofluorescene. Methods in general use (13) were adapted for detection of HPV. After, cytocentrifugation slides were air-dried and fixed in acetone at $4^{\circ} \mathrm{C}$ for $1 \mathrm{~min}$. Slides were precoated with normal goat serum diluted 1:5 in PBS- $0.2 \%$ bovine serum albumin (BSA) to block nonspecific binding. Washes were performed by dipping slides into PBS- $0.2 \%$ BSA. Anti-HPV antibodies used in the indirect immunofluorescent procedure included hybridoma supernatant from clone VRL/B19/11 (3) and purified IgG from ascites fluid (maximal concentration $2 \mathrm{mg} / \mathrm{ml}$ ) of the same clone; control sera included mouse IgG (Miles Laboratories Inc., Elkhart, IN), a monoclonal antibody to hepatitis B surface antigen (Hybritech Inc., LaJolla, CA), and nonimmune hybridoma supernatant. The area of the slide onto which cells had been pelleted was treated with $5 \mu \mathrm{l}$ of purified $\mathrm{IgG}$ or $50 \mu \mathrm{l}$ of hybridoma supernatants for $30 \mathrm{~min}$ at room temperature. After washing, $50 \mu l$ of affinity purified, fluorescein-conjugated goat antimouse gamma chain (Kirkegaard and Perry, Gaithersburg, Maryland) diluted 1:50 in PBS was added for $\mathbf{3 0} \mathrm{min}$ at room temperature. After final washing and air-drying, slides were mounted using neutral $5 \%$ $n$-propyl gallate in glycerol and examined with a Universal III photo microscope (Carl Zeiss, Oberkochen, Federal Republic of Germany) which employed an XBO 150 xenon lamp and standard Zeiss filters for epifluorescence of fluorescein.

Electron microscopy. $(14,15)$. In order to recover sufficient cells for examination by electron microscopy, special care was taken in harvesting cells from culture. Immature bursts removed from tissue culture media were washed three times in PBS in 1.5-ml polypropylene micro-tubes by centrifugation at $1,200 \mathrm{rpm}$ in a Sorvall RT 6000 centrifuge (DuPont Instruments, Newtown, CT) at $4^{\circ} \mathrm{C}$. Supernatants were removed by gentle aspiration. Cells were fixed by exposure to $2 \%$ electron microscope grade glutaraldehyde (Polysciences, Inc., Warrington, PA) in PBS for 25 min at $4^{\circ} \mathrm{C}$ and postfixed with $1 \%$ osmium tetroxide (Polysciences, Inc.) for $1 \mathrm{~h}$ at $4^{\circ} \mathrm{C}$. After removing excess osmium tetroxide by washing, one drop of $12.5 \%$ human serum albumin was added and the cells were immediately centrifuged. The resulting gel allowed the cell pellet to be treated as a small block during dehydration and embedding in Epon 812 (Ladd Research Industries, Inc., Burlington, VT). After polymerization, trimmed blocks were cut into $600 \mathrm{~A}$ sections, placed onto 300 mesh copper grids (Ted Pella Inc., Irvine, CA), double stained with uranyl acetate (LKB Instruments, Gaithersburg, Maryland), followed by staining with lead citrate (LKB), and examined and photographed using a Zeiss EM-10 electron microscope (Carl Zeiss, Oberkochen, Federal Republic of Germany) at $60 \mathrm{kV}$ acceleration voltage.

\section{Results}

In situ observations of HPV-infected progenitor cells. Infection with HPV of the cells of an immature erythroid burst, which represent a population of erythroid progenitor cells similar to CFU-E, results in severe reduction of secondary colony formation (11). Detection of colonies requires both cell proliferation and erythroid differentiation, and apparent decreased colony formation could be the result of interruption of either process. Serial observations of replated erythroid colonies by light microscopy showed that HPV-infected cells failed to proliferate. Progressive doubling of cells and formation of 1664 cell colonies, accompanied by gradual hemoglobinization, were visible in the control, uninfected cultures (Fig. $1 B$ ). In the plates treated with HPV, however, no growth beyond the four-cell stage of colony formation was seen (Fig. $1 A$ ). At this point, 24-48 $\mathrm{h}$ after plating in fresh medium, the cells within these abortive colonies showed crenated outer surfaces and loss of the normal refractile appearance of healthy cells.

Immunofluorescent detection of HPV using a monoclonal antibody. To detect HPV in infected erythroid progenitor cells, immature bursts were removed from culture and exposed to HPV-containing or control sera for $2 \mathrm{~h}$. Cytocentrifuge preparations were made from aliquots of infected and control cells immediately after the $2 \mathrm{~h}$ incubation with sera, and 24, 48, and $72 \mathrm{~h}$ after replating in fresh medium. Both hybridoma supernatant and purified antibody from ascites fluid allowed detection of a specific pattern of fluorescence in HPV-infected erythroid cells (Fig. 2). At 24-48 h after exposure, particulate fluorescence was observed mainly in the cytoplasm in 5-10\% of cells; nuclear fluorescence was also observed in occasional cells (Fig. 2, $A$ and $B$ ). Cell preparations at 2 and $72 \mathrm{~h}$ showed no specific fluorescence. The specificity of staining with the monoclonal antibody was confirmed by examination of HPVinfected cells that were stained with mouse IgG, a nonimmune hybridoma supernatant, anti-hepatitis B surface antigen antibody (Fig. $2 C$ ), and uninfected erythroid cells that were stained with anti-HPV monoclonal antibody (Fig. 2 D).

Ultrastructural changes in HPV-infected progenitors. Uninfected immature erythroid cells showed ultrastructural features that have been associated with erythroid progenitors in methylcellulose culture $(16,17)$ : single large and slightly irregular nuclei; small numbers of mitochondria; scanty endoplasmic reticulum; abundant polyribosomes; infrequent small cytoplasmic vacuoles; and ferritin particles in small vesicles (Fig. $3, E$ and $F$ ). Progenitor cells examined immediately after a 2-h incubation with HPV-containing serum appeared normal. Cells that had been incubated with HPV and then cultured for 24-48 h showed major morphologic alterations. The cytoplasm showed marked vacuolization and pseudopod formation (Fig. 3, $A-C$ ); the mitochondria of infected cells were 


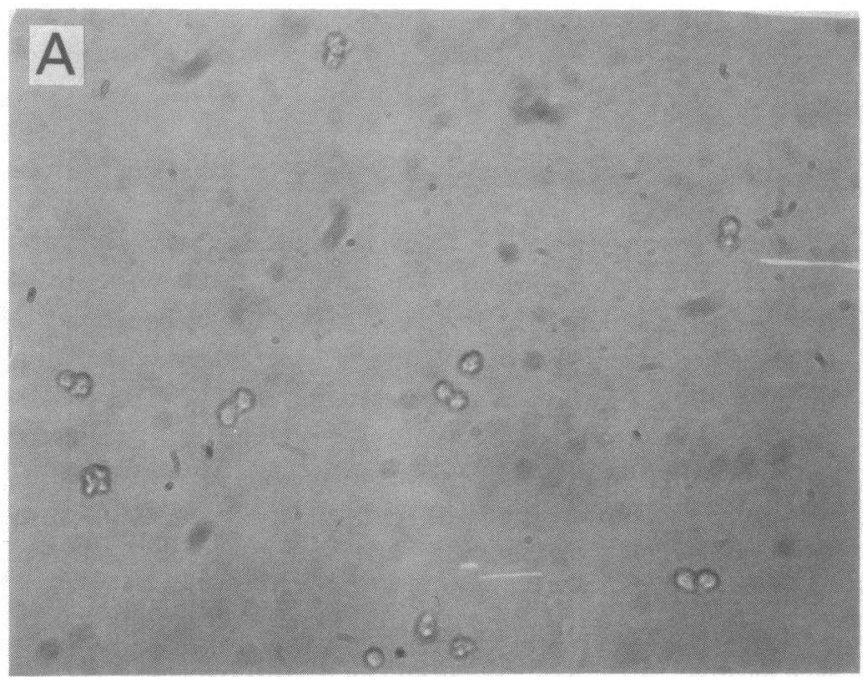

Figure 1. The appearance of developing secondary erythroid colonies in situ after replating. In this experiment, 30 developing bursts were identified by their morphologic characteristics and removed with a micropipette from primary methylcellulose culture. After exposure to

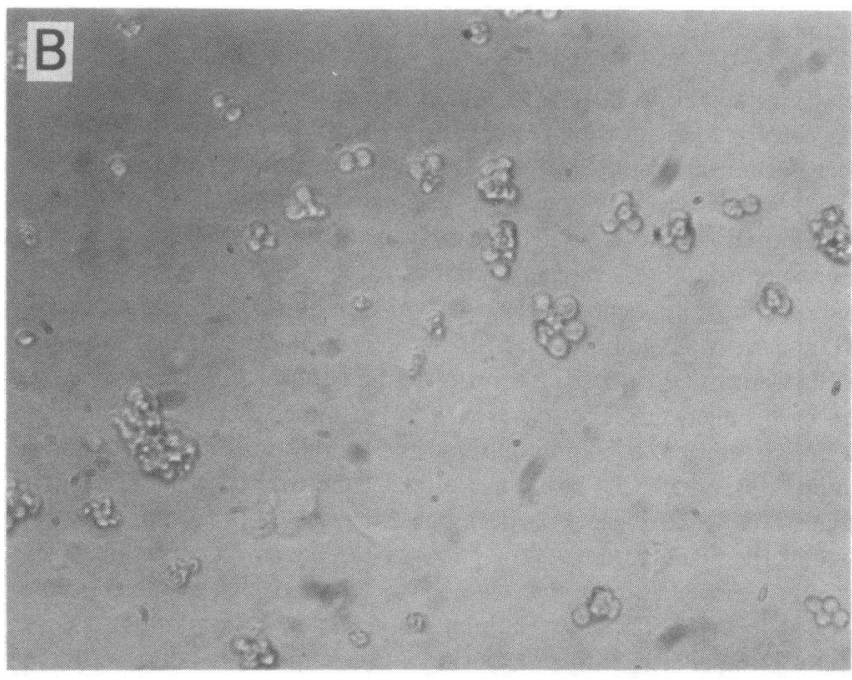

HPV-containing $(A)$ or normal $(B)$ sera for $2 \mathrm{~h}$ at $4^{\circ} \mathrm{C}$, the cells were replated in fresh culture medium for $48 \mathrm{~h}$. The infected progenitor cells did not proliferate beyond the four-cell stage. $\times 200$ (Polaroid type 665, Zeiss inverted microscope).
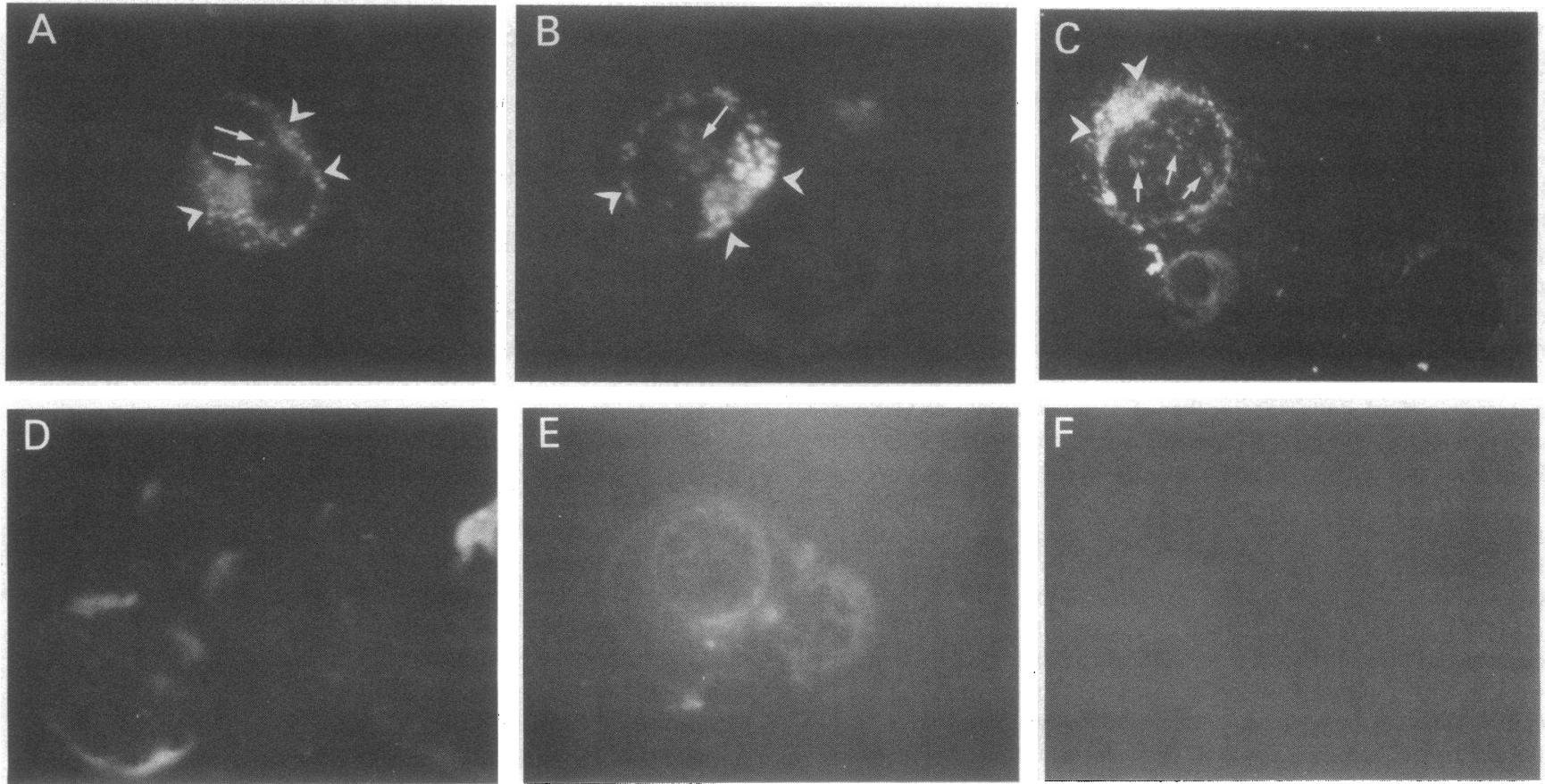

Figure 2. Immunofluorescence of isolated erythroid cells. Cells of immature bursts plucked from primary methylcellulose culture were exposed for $2 \mathrm{~h}$ at $4^{\circ} \mathrm{C}$ to either HPV-containing sera $(A-D)$ or control sera $(E, F)$ and cultured in fresh methylcellulose for 24-48 h. A specific pattern of particulate green fluorescence was observed mainly in the cytoplasm (large arrowheads) but also in the nucleus (small arrows) of infected cells on staining with anti-HPV hybridoma supernatant $11(A-C)$. Only a nonspecific, diffuse yellow color was observed on staining of HPV-infected cells using hepatitis B surface antigen monoclonal antibody $(D)$ or nonimmune hybridoma supernatant or mouse IgG (not shown), nor was specific fluorescence observed when uninfected cells were stained with hybridoma supernatant $11(E, F)$. Automatic, full exposure of the film was used to photograph $A-D$ and for the control $E$; for control cells in $F$, the exposure time was adjusted to be identical to that of infected cells (41/2 min). $\times 840$ (Kodak Ektachrome ASA 400, Zeiss microscope). 

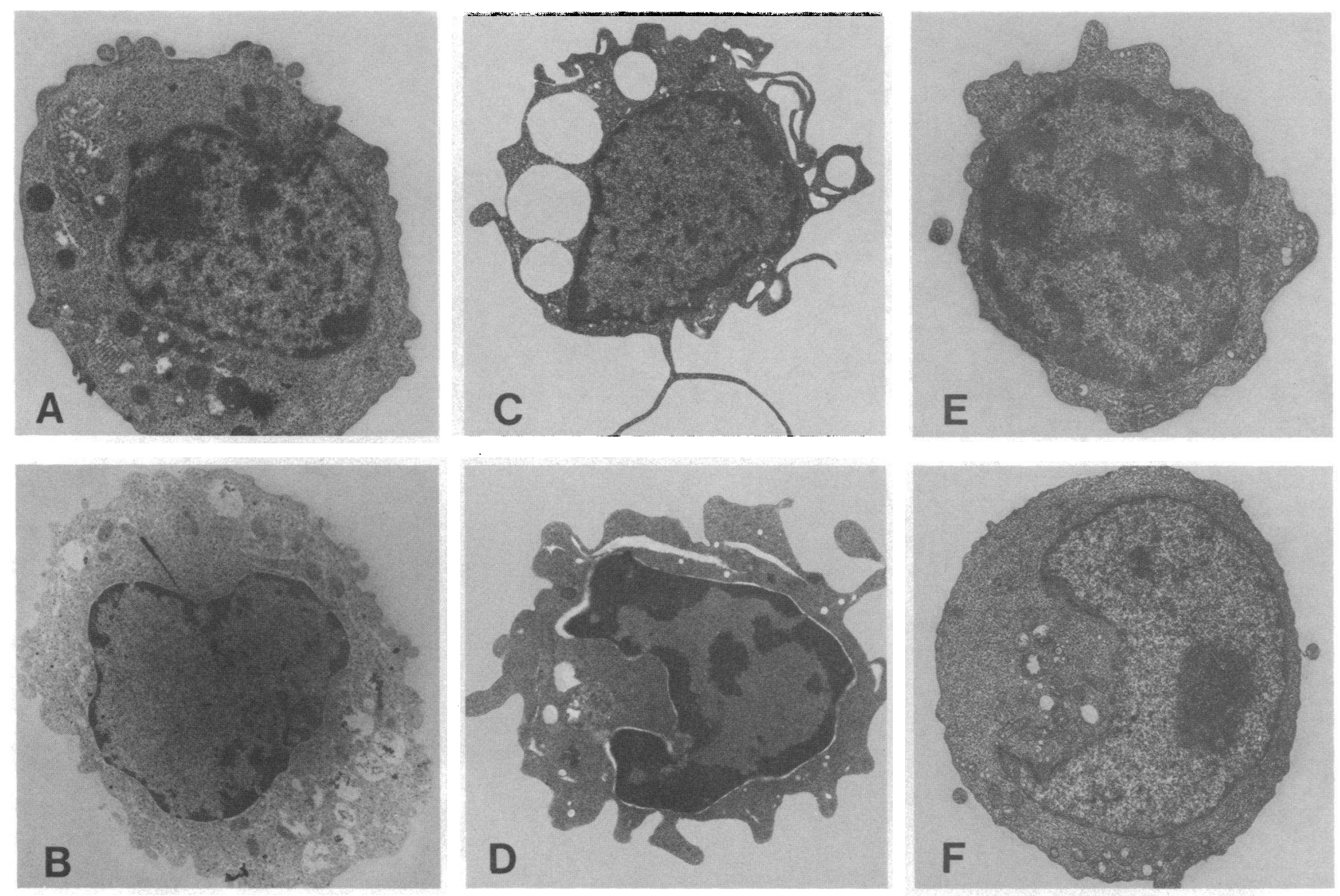

Figure 3. Electron micrographs of HPV-infected erythroid progenitor cells. Immature bursts were isolated as described in the legend to Fig. 1 and incubated with HPV-containing or normal sera. Photomicrographs shown were obtained at $2 \mathrm{~h}(A), 16 \mathrm{~h}(B)$, and $48 \mathrm{~h}(C, D)$ after initial infection and subsequent growth in fresh culture me- dium; uninfected cells at $48 \mathrm{~h}$ after treatment with control serum are shown in $E$ and $F$. Infected cells at $48 \mathrm{~h}$ showed margination of the chromatin, extreme vacuolization, pseudopod formation, and shrunken mitochondria. $X \sim 10,000$ (Kodak 4489 film, Zeiss microscope).

irregular clumps of viruslike particles were observed in cytoplasmic vacuoles (data not shown).

\section{Discussion}

Morphologic studies of normal bone marrow cells infected with HPV and grown in methylcellulose show that this virus is cytotoxic for an erythroid progenitor cell and that parvoviruslike structures can be demonstrated in the nucleus and cytoplasm of these cells by electron microscopy. The technique of reculture of progenitor cells offers the advantage of isolation of erythroid cells at a defined stage of erythroid differentiation. However, the use of sera as a source of virus and isolated bone marrow cells as targets is not directly comparable to infection of synchronized cell populations with purified virus stocks. Because erythroid cells undergo terminal differentiation 


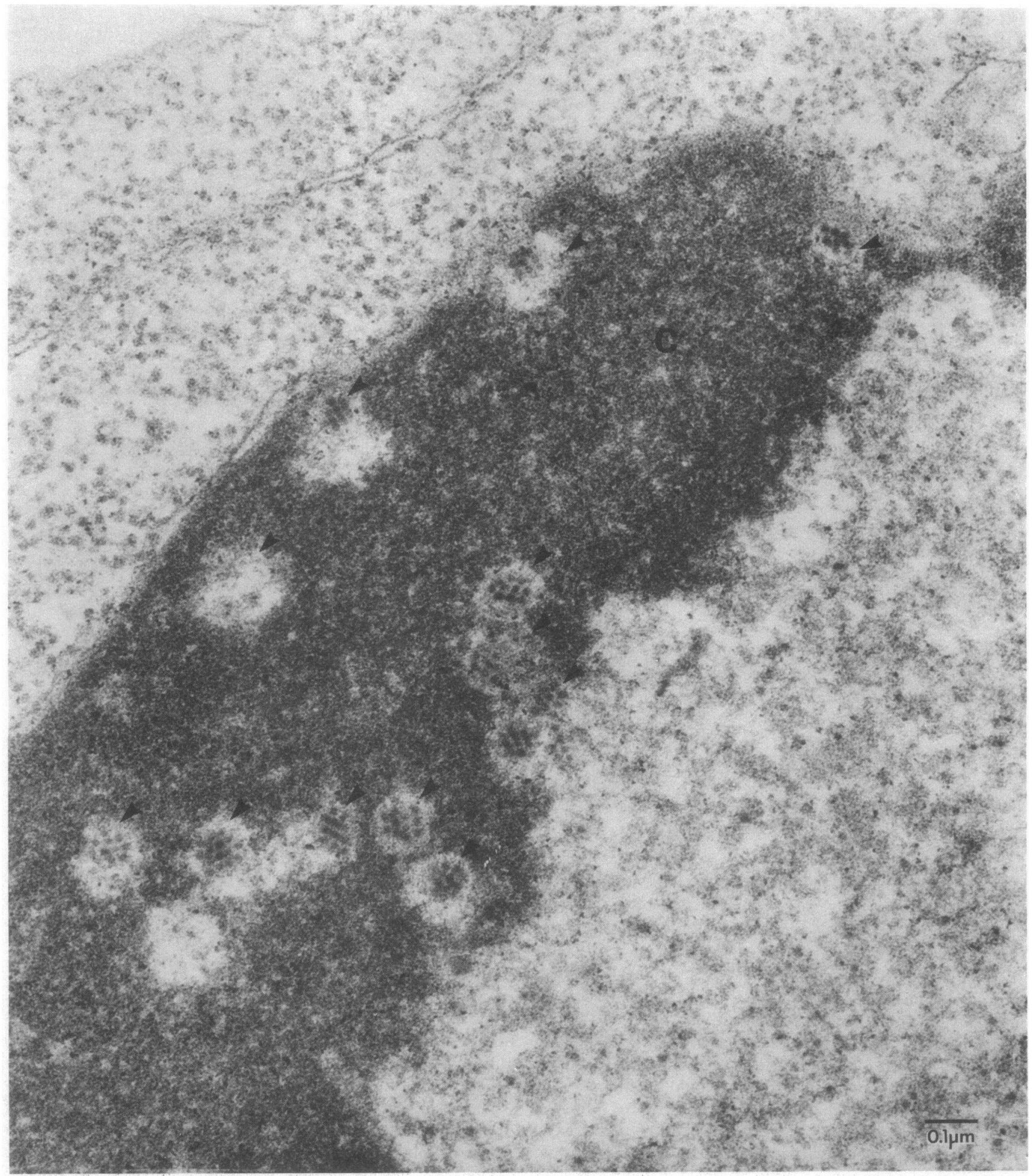

Figure 4. Area of marginated chromatin of HPV-infected erythroid progenitor cell. Bone marrow cells were isolated, infected for $48 \mathrm{~h}$, and cultured as described in the legend to Fig. 1. Within the margin- ated chromatin (c), there are many lacunae (arrows) containing crystalline arrays of parvovirus-like structures. $\times 100,000$ (Kodak 4489 film, Zeiss microscope). 


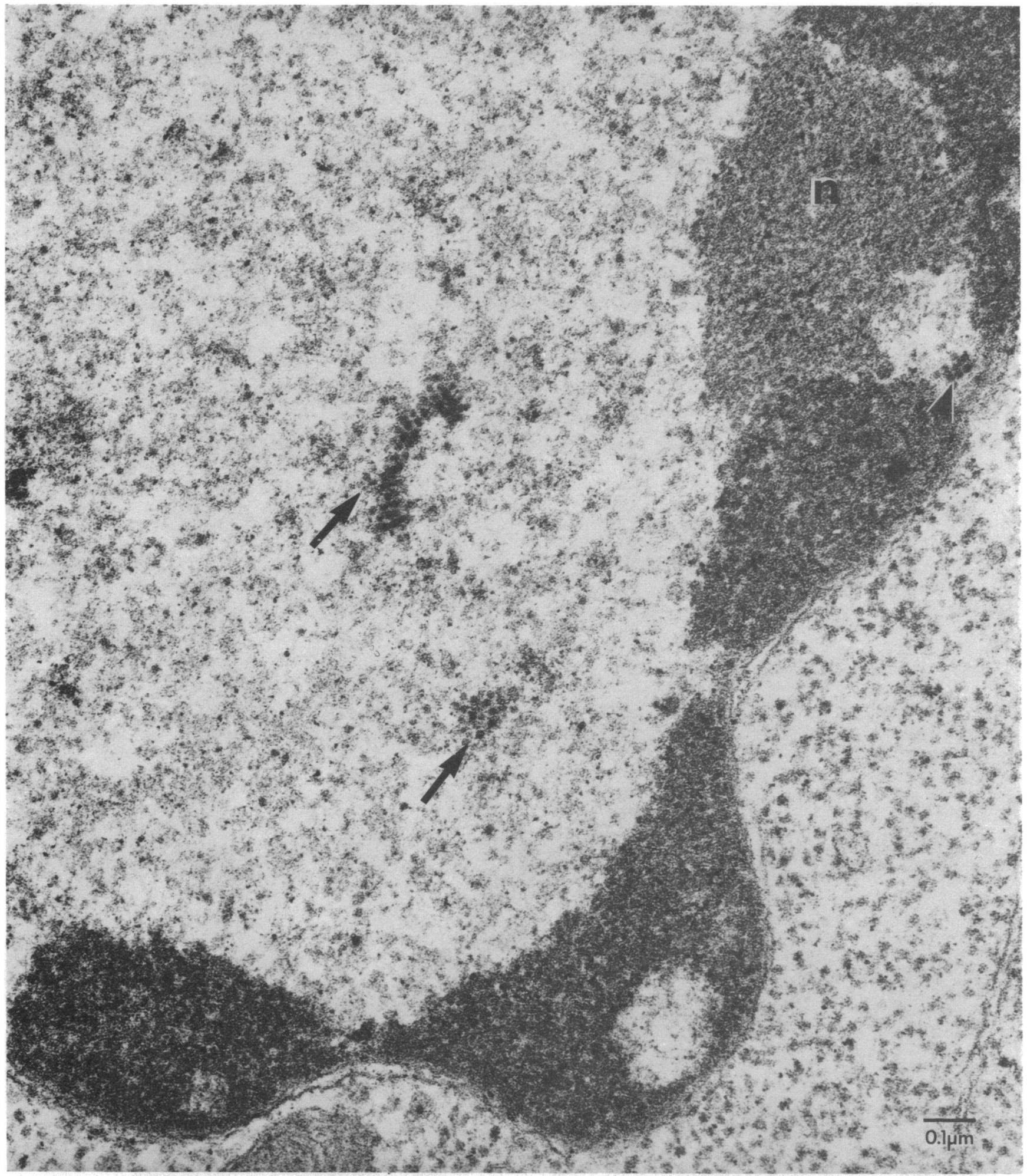

Figure 5. Nuclear interior and nucleolus of HPV-infected erythroid progenitor cell. Cells were isolated, infected, and recultured for $48 \mathrm{~h}$ as described in the legend to Fig. 1 . The nucleolus (n) is abnormally granular in appearance. Parvovirus-like structures are seen both within lacuane in the marginated chromatin (arrowhead) and in the interior of the nucleus (arrows). $\times 100,000$ (Kodak 4489 film, Zeiss microscope). 


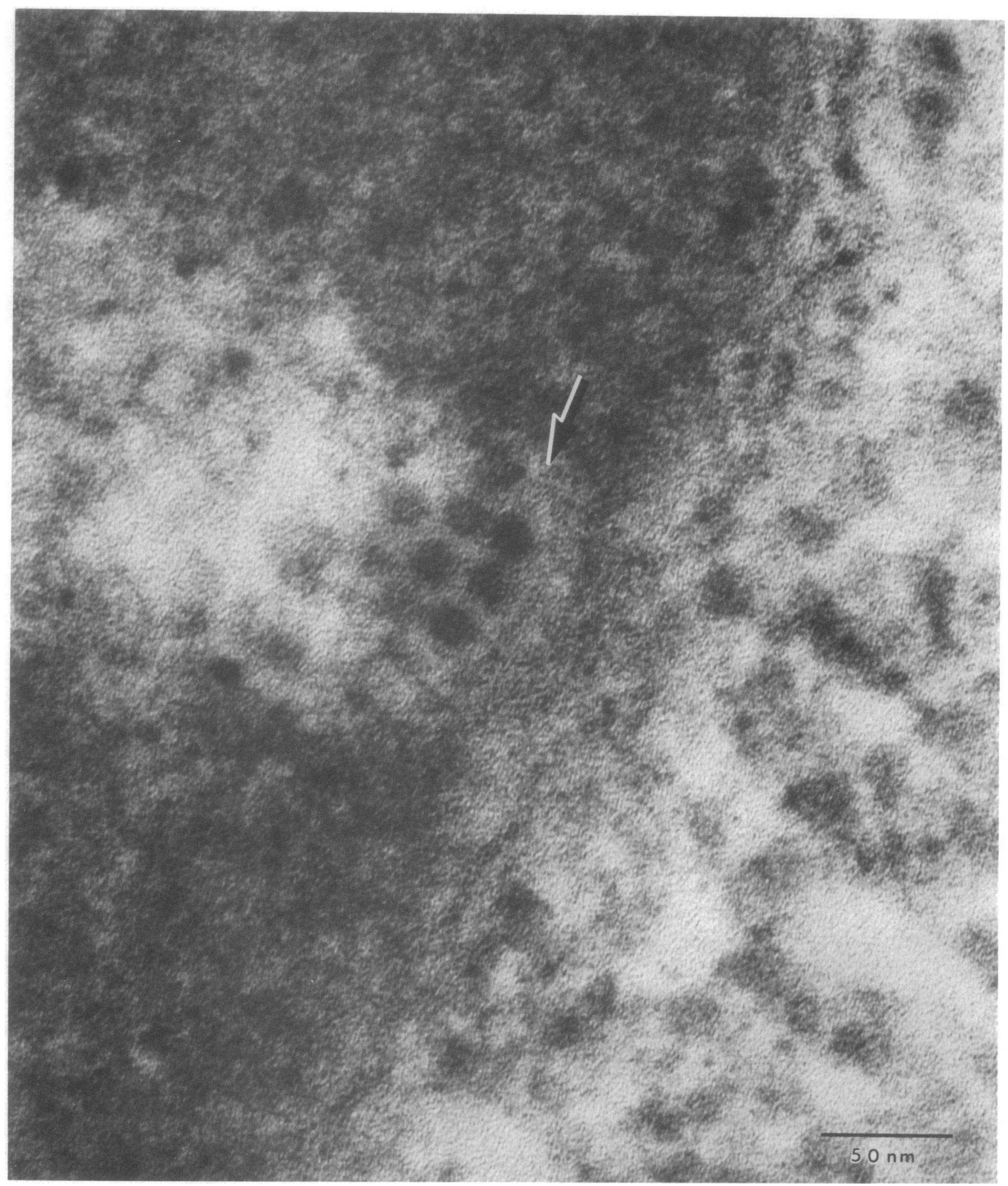

Figure 6. Parvovirus-like particles in the nucleus of an HPV-infected cell. Bone marrow erythroid progenitor cells were isolated, infected, and recultured for $48 \mathrm{~h}$ as described in the legend to Fig. 1. The virus-like particles (arrow) were icosahedral and measured on average of $18 \mathrm{~mm}$ in diameter, which is consistent with the structural features of a parvovirus. $\times 500,000$ (Kodak 4489 film, Zeiss microscope). 
to a nonproliferative state, the methylcellulose system would be unlikely to support sustained parvovirus replication, which is very dependent on a substrate of actively dividing cell hosts $(18,19)$. The usual time course of parvovirus infection in vitro begins with virus absorption within $1-2 \mathrm{~h}$, followed by a latent period of 10-16 h, and expression of complete virus particles at 24-30 h (18, 20-22). In the experiments reported here with HPV, maximal expression was detected by immunofluorescence and electron microscopy at $48 \mathrm{~h}$, but the large sampling errors and small amount of virus detected preclude conclusions regarding real differences in the kinetics of infection by HPV compared to other parvoviruses.

Our observations point to some important aspects of HPV infection of human bone marrow cells. First, like other parvoviruses $(18,19,21), \mathrm{HPV}$ is cytotoxic for its host cells. In situ observations indicate that infected cells fail to proliferate, and that the effect of HPV is not therefore due to a block in differentiation alone. Infected cells also show cytoplasmic ultrastructural changes associated with toxicity, including vacuolization, mitochondrial deformity, and pseudopod formation.

Second, only a minor proportion of infected cells had evidence of HPV replication by immunofluorescence. In contrast, the functional effect of in vitro HPV infection is to eliminate almost completely secondary erythroid colony formation (11). HPV infection might be expected to be very efficient, as so high a proportion of CFU-E are sensitive to cell-cycle specific agents (23). The viral product detected by the monoclonal antibody may not be expressed in all infected cells. The parvovirus genome also encodes for nonstructural proteins that may alter normal cell regulation $(24,25)$, and expression of capsid proteins may not be required to cause cell death (Tattersall, P., personal communication).

HPV infection of erythroid progenitors may not lead to production of infectious virions. We have been unable to passage virus from either methylcellulose or suspension cultures of erythroid bone marrow (Young, N., and J. Moore, unpublished data). Nor has HPV been successfully propagated in culture, despite efforts to infect many different cell types including such rapidly proliferating cell lines as African green monkey kidney cells, feline kidney cells, murine myeloma cells, and human fibroblasts, and lymphoid leukemia and erythroleukemia cells (Young, N., and J. Moore; P. Mortimer, unpublished data). Abortive and replication defective production of HPV in progenitor cells in vitro may account for the absence of the pattern of diffuse nuclear fluorescence described in some studies of human adeno-associated viruses (26). The punctate nuclear fluorescence observed with HPV infection was consistent with the relatively small lacunae containing virus particles seen on electron microscopy.

Third, while some parvoviruses, like the human adenoassociated viruses, require co-infection with a second virus in order to successfully replicate, there was no evidence from electron microscopy of a second, morphologically distinct virus proliferating in infected bone marrow cells. Although some biochemical studies have suggested similarities between HPV and the human adeno-associated viruses $(8,9)$, the molecular features of the cloned virus link it evolutionarily to the helper independent parvoviruses of rodents rather than to human adeno-associated viruses (27). The molecular basis for the fastidious behavior of HPV in tissue culture therefore remains uncertain.

Finally, the appearance of HPV in nuclei is similar to that described for other parvoviruses $(21,22,28,29)$. Viruslike particles were present in the marginated chromatin in clumps and crystalline arrays; by analogy with other parvoviruses, it is likely that virus is manufactured in the interior of the nucleus, employs the nucleolus in its replication, and is transported outwards to the cytoplasm. The $18 \mathrm{~nm}$ particle size of HPV in thin tissue section, though smaller than the 23 $\mathrm{nm}$ size of HPV in immune precipitated sera (2), is comparable to the size of other animal parvovirus in tissue sections (29, 30). Also, in contrast to the appearance of HPV in sera was the absence in tissue sections of empty capsids.

These morphologic studies complement functional studies in establishing that the pathogenesis of the transient aplastic crises of hereditary hemolytic anemias is cytotoxicity of HPV for bone marrow erythroid progenitor cells. The availability of molecular probes for the HPV genome (27) should facilitate the study of possible HPV involvement in chronic forms of bone marrow failure and in other diseases.

\section{Acknowledgments}

We thank Drs. Naomi Luban and Jack Kelleher for providing sera JB and $\mathrm{JH}$. We are grateful for the expert advice in immunofluorescent technique provided by Dr. Stephen Lippman. Drs. David Hoggan, James Rose, and Peter Tattersall were very helpful in the interpretation of our data.

\section{References}

1. Siegl, G. 1976. The Parvoviruses. Springer-Verlag, Vienna, Austria. 1-109.

2. Cossart, Y. E., B. Cant, A. M. Field, and D. Widdows. 1975. Parvovirus-like particles in human sera. Lancet. I:72-73.

3. Cohen, B. J., P. P. Mortimer, and M. S. Pereira. 1983. Diagnostic assays with monoclonal antibodies for the human serum parvoviruslike virus. J. Hygiene (Cambridge). 91:113-130.

4. Pattison, J. R., S. E. Jones, J. Hodgson, L. R. Davis, J. M. White, C. E. Stroud, and L. Murtaza. 1981. Parvovirus infections and hypoplastic crisis in sickle-cell anemia. Lancet. I:664-665.

5. Sergeant, G. R., K. Mason, J. M. Topley, B. E. Sergeant, J. R. Pattison, S. E. Jones, and R. Mohamed. 1981. Outbreak of aplastic crises in sickle-cell anemia associated with parvovirus-like agent. Lancet. II:595-597.

6. Young, N., and P. P. Mortimer. 1984. Viruses and bone marrow failure. Blood. 63:729-737.

7. Anderson, M. J., S. E. Jones, S. P. Fisher-Hoch, E. Lewis, S. M. Hall, C. L. R. Bartlett, B. J. Cohen, P. P. Mortimer, and M. S. Pereira. 1983. Human parvovirus, the cause of erythrema infectiosum (fifth disease)? Lancet. I:1378.

8. Summers, J., S. E. Jones, and M. J. Anderson. 1983. Biochemical 
characterization of the genome of the agent of erythrocyte aplasia permits its classification as a human parvovirus. J. Gen. Virol. 64:25272532.

9. Clewley, J. P. C. 1984. Biochemical characterization of human parvovirus. J. Gen. Virol. 65:241-245.

10. Mortimer, P. P., R. K. Humphries, J. G. Moore, R. H. Purcell, and N. Young. 1983. A human parvovirus-like virus inhibits hematopoietic colony formation in vitro. Nature (Lond.). 302:426-429.

11. Young, N., P. P. Mortimer, J. G. Moore, and R. K. Humphries 1984. Characterization of a virus that causes transient aplastic crisis J. Clin. Invest. 73:224-230.

12. Humphries, R. K., A. C. Eaves, and C. J. Eaves. 1981. Selfrenewal of hemopoietic stem cells during mixed colony formation. Proc. Natl. Acad. Sci. USA. 78:3629-3633.

13. Kawamura, A., Jr., editor. 1977. Fluorescent Antibody Techniques and their Applications. University Park Press, Baltimore. 1292.

14. Hayat, M. A. 1970. Principles and Techniques of Electron Microscopy; Biological Applications, Vol. 1. Van Nostrand Reinhold, New York. 87-94, 241-274, 346.

15. Luft, J. H. 1973. Embedding media-old and new. In Advanced Techniques in Biological Electron Microscopy. Vol. 1. J. K. Koehler, editor. Springer-Verlag New York Inc., New York. 1-31.

16. Ogawa, M., R. T. Parmley, H. L. Bank, and S. S. Spicer. 1976. Human marrow erythropoiesis in culture. I. Characterization of methylcellulose assay. Blood. 48:407-417.

17. Parmley, R. T., M. Ogawa, S. S. Spicer, H. L. Bank, and N. J. Wright. 1978. Human marrow erythropoiesis in culture: III. Ultrastructural and cytochemical studies of cellular interactions. Exp. Hemat. 6:78-90.

18. Rose, J. A. 1975. Parvovirus reproduction. In DNA Animal Viruses, Comprehensive Virology, Vol. 3. H. Fraenkel-Conrat and R. Wagner, editors. Plenum Press, New York. 1-61.

19. Tattersall, P., and D. Ward. 1978. The parvoviruses-an introduction. In Replication of Mammalian Parvoviruses. D. C. Ward and P. Tattersall, Cold Spring Harbor Laboratory, Cold Spring Harbor, New York. 3-12.
20. Paradiso, R. P., S. L. Rhode, and I. I. Singer. 1982. Canine parvovirus: a biochemical and ultrastructural characterization. J. Gen. Virol. 62:113-125.

21. Singer, I. I., and S. L. Rhode. 1977. Ultrastructural studies of H-1 parvovirus replication. IV. Crystal development and structure with the temperature-sensitive mutant ts 1 . J. Virol. 24:343-352.

22. Richards, R., P. Linser, and R. W. Armentrout. 1978. Maturation of minute-virus-of-mice particles in synchronized rat brain cells. In Replication of Mammalian Parvoviruses. D. C. Ward and P. Tattersall, editors. Cold Spring Harbor Laboratory, Cold Spring Harbor, New York. 447-453.

23. Eaves, C. J., R. K. Humphries, and A. C. Eaves. 1979. In vitro characterization of erythroid precursor cells and the erythropoietic differentiation process. In Cellular and Molecular Regulation of Hemoglobin Switching. G. Stamatoyannopoulos and A. W. Nienhuis, editors. Grune and Stratton Inc., New York. 251-278.

24. Rhode, S. L., and P. R. Paradiso. 1983. Parvovirus genome: nucleotide sequence of $\mathrm{H}-1$ and mapping of the genes by hybrid-arrest translation. J. Virol. 45:173-184.

25. Cotmore, S. F., L. J. Sturzenbecker, and P. Tattersall. 1983. The autonomous parvovirus MVM enodes two nonstructural proteins in addition to its capsid polypeptides. Virology. 129:333-343.

26. McPherson, R. A., H. S. Ginsberg, and J. A. Rose. 1982. Adeno-associated virus helper activity of adenovirus DNA binding protein. J. Virol. 44:666-673.

27. Cotmore, S. F., and P. Tattersall. Characterization and molecular cloning of a human parvovirus gene. Science (Wash. $D C$ ). In press.

28. Singer, I. I., and S. L. Rhode. 1977. Ultrastructural studies of H-1 parvovirus replication. V. Immunocytochemical demonstration of separate chromatin-associated and inclusion-associated antigens. $J$. Virol. 24:353-362.

29. Yasoshima, A., K. Doi, A. Kojima, and A. Okaniwa. 1982. Electron microscopic findings on epithelial cells of Lieberkuhn's crypts in canine parvovirus infection. Jap. J. Vet. Sci. 44:81-88.

30. Field, A. M. 1982. Diagnostic virology using electron microscopy. Adv. Virus Res. 27:1-69. 